\title{
Non-volcanic crustal movements of the northernmost Philippine Sea plate detected by the GPS-acoustic seafloor positioning
}

\author{
Shun-ichi Watanabe*, Tadashi Ishikawa and Yusuke Yokota
}

\begin{abstract}
Repeatedly performing the GPS-acoustic seafloor positioning, we first succeeded in detecting non-volcanic seafloor movements on the Philippine Sea plate (PHS) subducting along the Sagami Trough. At a seafloor geodetic site on the northernmost part of the PHS off the Boso Peninsula, we detected significant eastward motion with respect to the central part of the PHS. This is unaccountable by the coupling between the Pacific plate and the PHS along the Izu-Bonin (Ogasawara) Trench because it would cause the westward elastic deformation at BOSS. It is rather consistent with the rigid motion of the tectonic block in the fore-arc along the Izu-Bonin Trench, associated with the back-arc rift. The other site on the western side of the Sagami Bay had moved toward the north relative to the Izu Peninsula. It suggests that the Izu microplate obviously moves relative to the northern PHS. The difference between the velocities of the Sagami Bay and the Izu Peninsula indicates the coupling on the boundary fault as well.
\end{abstract}

Keywords: GPS-acoustic, Seafloor geodetic observation, Philippine Sea plate, Sagami Trough, Izu arc, Izu microplate, Plate motion

\section{Introduction}

The northernmost part of the Philippine Sea plate (PHS) subducts beneath the North American plate (NA) along the Sagami Trough. In this region, thrust earthquakes such as the 1923 Taisho Kanto earthquake (M7.9) and the 1703 Genroku Kanto earthquake (M7.9-8.2) had occurred repeatedly. Additionally, slow slip events off the Boso Peninsula with a recurrence interval of several years have been observed (e.g., Ozawa, 2014). In the northern side of the PHS, the Izu microplate (IM) is considered to move relative to the PHS, whose boundary is located on the west edge of the Sagami Bay (e.g., Sagiya, 1999). The IM subducts beneath the Eurasian plate (EU) along the Suruga Trough, where a large earthquake had occurred in 1854 (Ando, 1975). In order to investigate the accumulation and/or the release of strain on the plate interface, it is necessary to estimate the precise convergence rate of the subducting oceanic plate relative to the continental plates, as Yasuda et al. (2014) had directly investigated in the Suruga Trough. They

\footnotetext{
* Correspondence: eisei@jodc.go.jp

Hydrographic and Oceanographic Department, Japan Coast Guard, 2-5-18 Aomi, Koto-ku, Tokyo 135-0064, Japan
}

\section{Springer}

indicated the strong coupling in the shallow portion of the plate boundary from the seafloor geodetic observation.

On the other hand, researchers had estimated the motion of the PHS in the frame of the whole plate kinematics, with geological (e.g., Seno et al. 1993) and geodetic observations (e.g., Sella et al. 2002; DeMets et al. 2010). However, because the most part of the PHS is covered with ocean, the insufficiency of precise geodetic observations makes it difficult to reduce the indeterminacy of the velocities. Especially in the portion near the boundaries, the non-rigid deformation would affect the velocities on the PHS. One of such deformation is caused by back-arc rift along the Izu-Bonin (Ogasawara) Trench where the Pacific plate (PAC) subducts beneath the PHS (Taylor et al. 1991).

Nishimura (2011) divided the northern PHS into several tectonic blocks, one of which is the fore-arc along the Izu-Bonin Trench, to simultaneously evaluate the rigid velocities of blocks and elastic deformation due to the slip deficits on the boundary faults and the volcanic inflations using the GNSS sites. However, many geodetic sites on the PHS relatively near the Sagami Trough are 

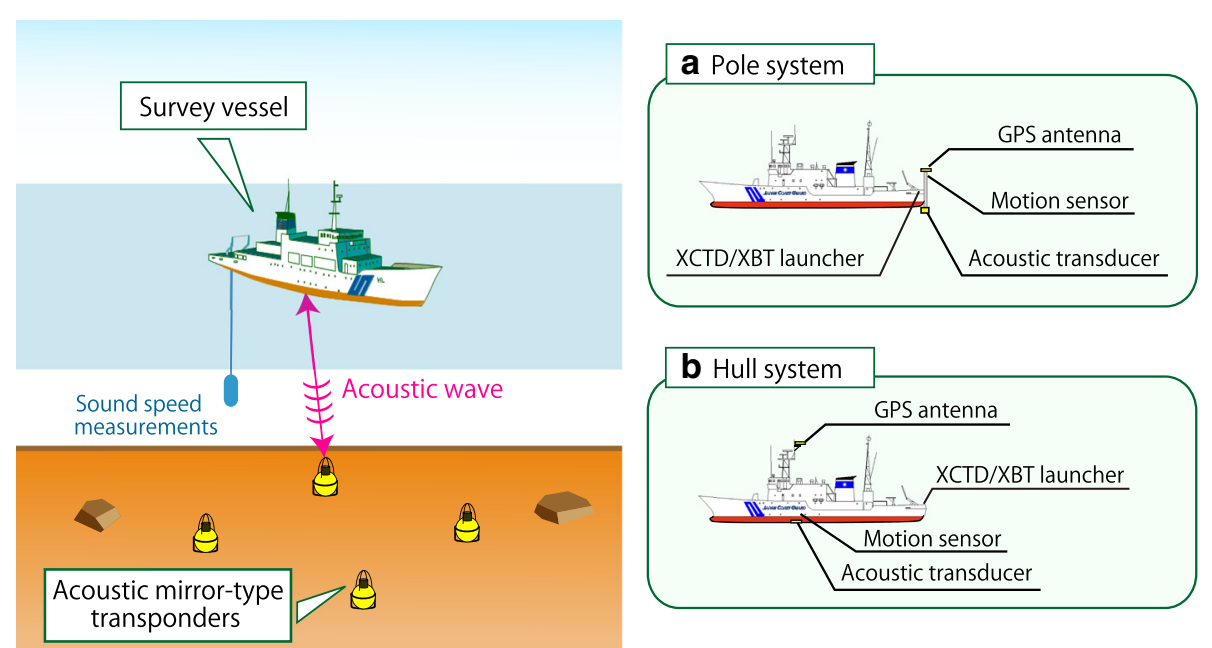

Fig. 1 GPS-acoustic observation system. a Pole system for drift observation. b Hull-mounted system for line-controlled sailing observation

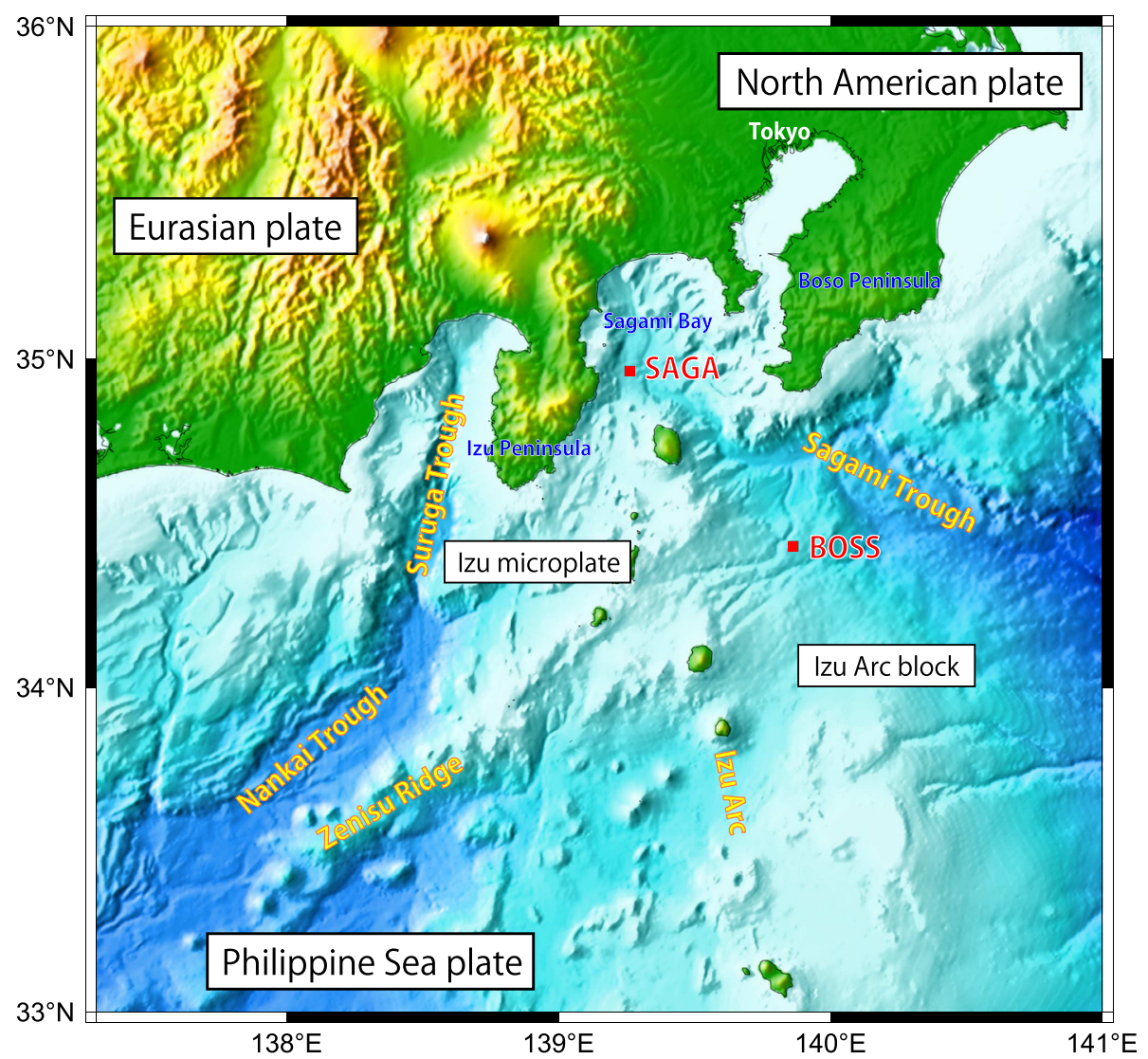

Fig. 2 Locations of the seafloor geodetic sites used in this paper; BOSS is located on the seafloor between the Sagami Trough and the Izu arc. SAGA is located on the flat seafloor in the Sagami Bay, between the Sagami Trough and the Izu microplate 
Table 1 Positions of seafloor sites

\begin{tabular}{lccl}
\hline Site name & Latitude (degree) & Longitude (degree) & Height $(\mathrm{m})$ \\
\hline BOSS & $34.42931 \mathrm{~N}$ & $139.86505 \mathrm{E}$ & -1409 \\
SAGA & $34.96106 \mathrm{~N}$ & $139.26318 \mathrm{E}$ & -1298 \\
\hline
\end{tabular}

located on the islands in the volcanic front, which would be the cause of the local deformation.

Thus, in order to obtain the non-volcanic geodetic data in the northernmost part of the PHS, we, the group of Japan Coast Guard (JCG), deployed the seafloor geodetic observation sites and have been carrying out the campaign observations since the middle of the 2000s. In this study, comparing the results of the seafloor observation to the models of crustal block kinematics, we clarified the motion of the northernmost PHS.

\section{Methods and observation data}

In order to detect seafloor movements with an accuracy of a few centimeters, GPS-acoustic combination technique has been developed (e.g., Spiess et al. 1998; Asada and Yabuki, 2001). In Japan, our group first succeeded in detecting seafloor movements caused by interseismic plate convergence at the Japan Trench (Fujita et al. 2006) and has continued to monitor the movements including coseismic and postseismic deformation at the seafloor sites along the Japan Trench (e.g., Matsumoto et al. 2006; Sato et al. 2011a, b; Sato et al. 2013b; Watanabe et al.
2014) and the Nankai Trough (e.g., Yokota et al. 2015). Moreover, other groups in Japan have provided important results (Kido et al. 2006; Kido et al. 2011; Tadokoro et al. 2012; Yasuda et al. 2014) to understand the major interplate earthquakes as well.

Figure 1 shows a schematic picture of the GPSacoustic positioning system developed by our group. The system consists of a sea-surface unit and a seafloor unit. The seafloor unit is a set of three or four acoustic mirror-type transponders. The transponders are installed on the seafloor to form an array of triangle or diamond whose diagonals are almost the same as water depth in the area. The sea-surface unit is a survey vessel with a GPS antenna, an undersea acoustic transducer, and a dynamic motion sensor. For the earlier stage of the observations, specifically before 2007, the onboard equipment was mounted at the stern of the vessel with an 8-m-long pole (Fig. 1a). In this pole system, the vessel should be adrift (drift observation). In 2008, we improved them to a hull-mounted system, where a transducer is equipped on the bottom of the vessel (Fig. 1b). It enables us to operate the sailing observation, in which we can control the track lines to collect spatially well-balanced data. Detailed methodologies and accuracy of this technique are discussed in Sato et al. (2013a).

The system measures the round-trip acoustic travel time between the sea-surface and seafloor units. The absolute position of the sea-surface unit is determined by kinematic
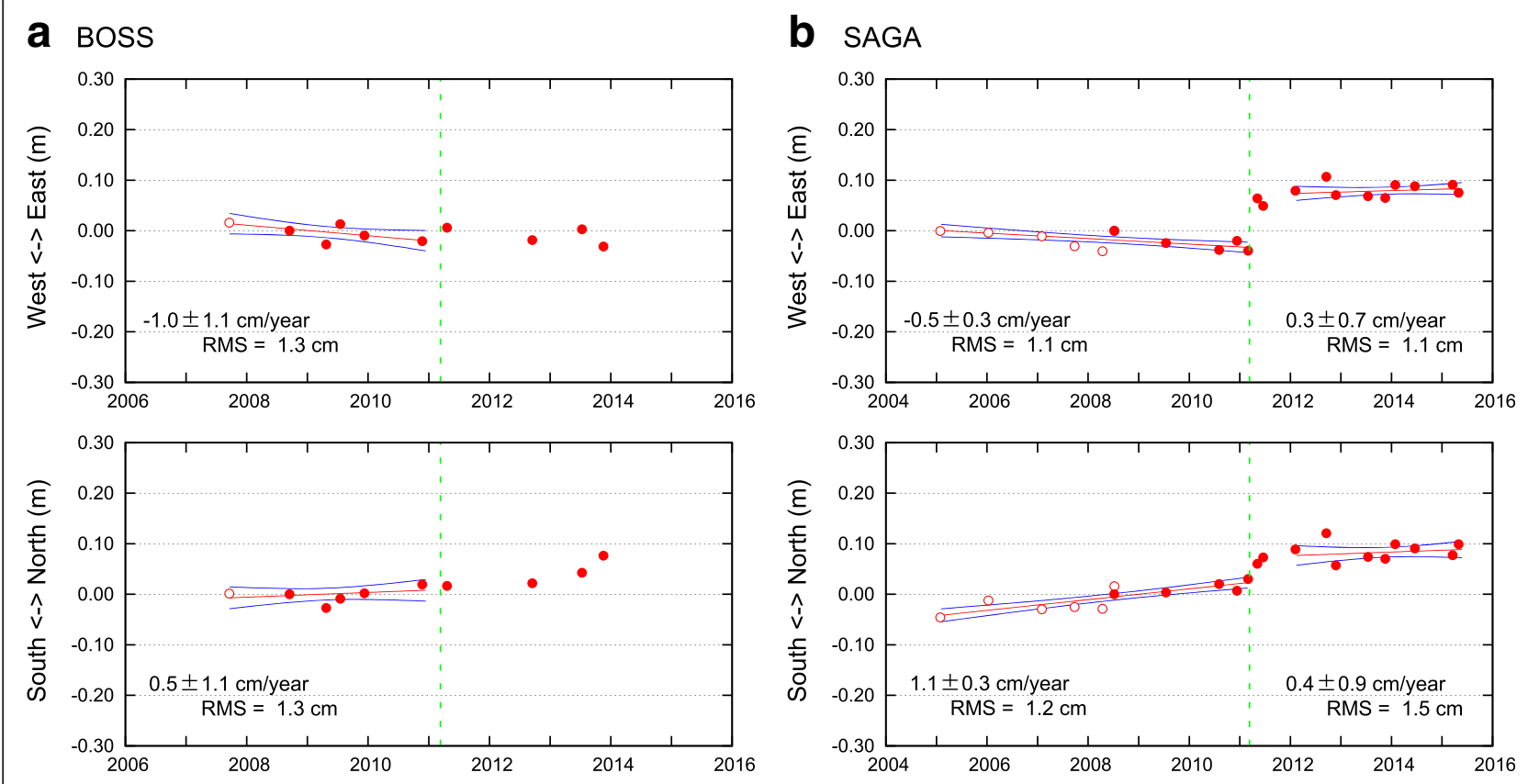

Fig. 3 Time series of estimated horizontal displacements of array centroid at (a) BOSS and (b) SAGA; the reference frame is the ITRF2005 (Altamimi et al. 2007). The open and solid red circles indicate the results from the drift observation and the sailing observation, respectively. The linear fitting using the M estimation method (a robust regression technique) and the $90 \%$ two-sided confidence intervals are shown with the red and blue lines, respectively. The green dashed lines indicate the occurrence time of the 2011 Tohoku-oki earthquake (M9.0) 
GPS. During the thousands shots of the acoustic ranging, the sound speed profile measurements are performed every several hours to calculate the distances between the units from the travel time.

We estimated positions of seafloor transponders based on the least squares formulation, simultaneously estimating the time variation of the sound speed (Fujita et al. 2006). In this method, we assume the horizontally layered structure for the sound speed profile. The position of the observation site is defined as the centroid of the transponder positions. In the analysis, we constrained the relative positions of the transponders to be those estimated from the data of all the sailing observation epochs in order to reduce estimation parameters in the least squares formulation (Matsumoto et al. 2008). The same strategy of analysis was also used in Watanabe et al. (2014) and Yokota et al. (2015).

Figure 2 and Table 1 show two observation sites used in this study. BOSS is located $50 \mathrm{~km}$ southern off Cape Nojima-saki, while SAGA is located in the Sagami Bay, $10 \mathrm{~km}$ eastern off Cape Kawana-saki. Both sites had been installed on the flat seafloor of the PHS along the Sagami Trough, distant from the active volcanoes (Izumi et al. 2013). We have performed 10 and 22 campaign observations at BOSS and SAGA during the periods from September 2007 to November 2013 and from January 2005 to April 2015, respectively.

\section{Results}

Figure 3 plots the estimated coordinates of the observation sites represented in the International Terrestrial Reference Frame 2005 (ITRF2005; Altamimi et al. 2007) by setting those of the first sailing observation epoch at each site as a reference. The relative positions of each epoch are shown in Table 2.

Linear fittings to each component of the displacement using the $\mathrm{M}$ estimation method (a robust regression technique) are also shown in Fig. 3, with the blue hyperbolic lines indicating the $90 \%$ two-sided confidence intervals. Before the Tohoku-oki earthquake (M9.0), we obtained the velocity of $1.0 \pm 1.1 \mathrm{~cm} /$ year westward and $0.5 \pm 1.1 \mathrm{~cm} /$ year northward and the velocity of $0.5 \pm 0.3 \mathrm{~cm} /$ year westward and $1.1 \pm 0.3 \mathrm{~cm} /$ year northward in the ITRF2005 with the $90 \%$ confidence at BOSS and SAGA, respectively. The linear fitting for BOSS after the Tohoku-oki earthquake is unavailable due to the uncertainty of estimation from only four epochs of observation. Meanwhile, at SAGA, apparently constant displacement rate of $0.3 \pm 0.7 \mathrm{~cm} /$ year eastward and $0.4 \pm 0.9 \mathrm{~cm} /$ year northward in the ITRF2005 was obtained after 2012. Moreover, from the discontinuous step of positions between just before and after the Tohoku-oki earthquake, eastward coseismic displacement of about $10 \mathrm{~cm}$ was detected at SAGA.
Table 2 Estimated relative site positions

\begin{tabular}{|c|c|c|}
\hline Epoch (year) & Eastward (m) & Northward (m) \\
\hline \multicolumn{3}{|l|}{ (a) BOSS } \\
\hline $2007.712^{a}$ & 0.0160 & 0.0015 \\
\hline 2008.704 & 0.0000 & 0.0000 \\
\hline 2009.309 & -0.0272 & -0.0270 \\
\hline 2009.542 & 0.0131 & -0.0089 \\
\hline 2009.939 & -0.0095 & 0.0019 \\
\hline 2010.893 & -0.0206 & 0.0194 \\
\hline 2011.301 & 0.0059 & 0.0165 \\
\hline 2012.706 & -0.0184 & 0.0219 \\
\hline 2013.526 & 0.0030 & 0.0426 \\
\hline 2013.879 & -0.0311 & 0.0763 \\
\hline \multicolumn{3}{|l|}{ (b) SAGA } \\
\hline $2005.076^{a}$ & -0.0005 & -0.0458 \\
\hline $2006.027^{a}$ & -0.0039 & -0.0123 \\
\hline $2007.084^{a}$ & -0.0110 & -0.0296 \\
\hline $2007.731^{a}$ & -0.0304 & -0.0252 \\
\hline $2008.284^{a}$ & -0.0405 & -0.0287 \\
\hline 2008.517 & 0.0000 & 0.0000 \\
\hline $2008.520^{\mathrm{a}}$ & -0.0006 & 0.0160 \\
\hline 2009.539 & -0.0243 & 0.0037 \\
\hline 2010.589 & -0.0381 & 0.0203 \\
\hline 2010.942 & -0.0200 & 0.0069 \\
\hline 2011.164 & -0.0396 & 0.0301 \\
\hline 2011.347 & 0.0639 & 0.0602 \\
\hline 2011.463 & 0.0491 & 0.0731 \\
\hline 2012.101 & 0.0793 & 0.0887 \\
\hline 2012.712 & 0.1067 & 0.1207 \\
\hline 2012.901 & 0.0704 & 0.0572 \\
\hline 2013.534 & 0.0684 & 0.0740 \\
\hline 2013.876 & 0.0650 & 0.0702 \\
\hline 2014.073 & 0.0907 & 0.0991 \\
\hline 2014.463 & 0.0881 & 0.0907 \\
\hline 2015.208 & 0.0911 & 0.0773 \\
\hline 2015.326 & 0.0752 & 0.0991 \\
\hline
\end{tabular}

Reference frame is the ITRF2005 (Altamimi et al. 2007). Reference position is the first sailing observation epoch

${ }^{\mathrm{a} E p o c h}$ with drift observation

Figure 4 and Table 3 show the velocities before the Tohoku-oki earthquake, adjusted to values relative to the stable part of the EU, on the basis of the angular velocity presented by Altamimi et al. (2007). The ellipses in Fig. 4 indicate the $90 \%$ confidence level. The velocities at the terrestrial sites deployed by the Geospatial Information Authority of Japan are also shown in Fig. 4, which were derived from the daily coordinates of the GNSS Earth Observation Network 


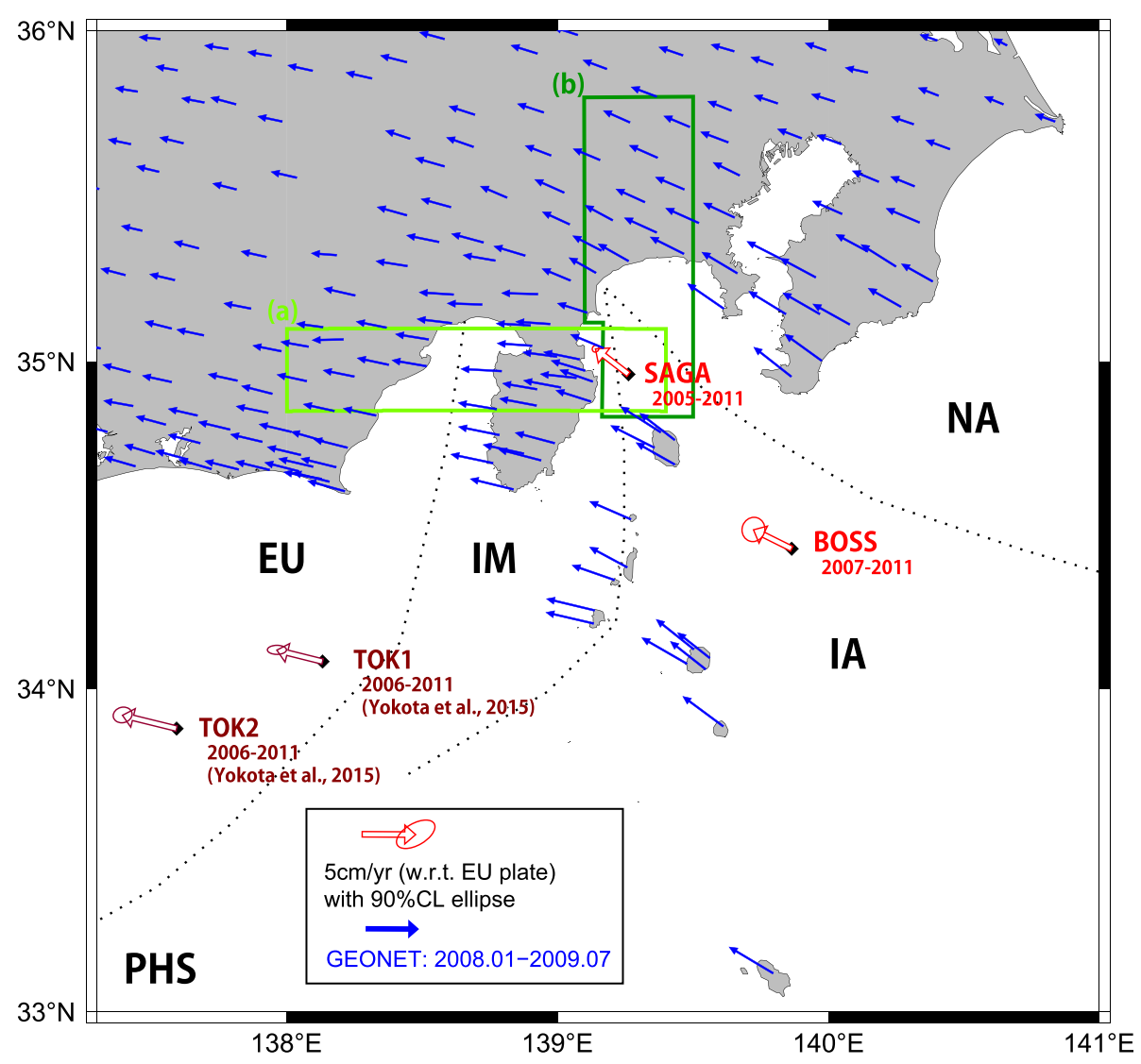

Fig. 4 Horizontal velocities relative to the Eurasian plate before the Tohoku-oki earthquake in the Kanto district; the red arrows and the brown arrows indicate the velocities at the seafloor sites detected in this paper and by Yokota et al. (2015), respectively, with $90 \% \mathrm{CL}$ (ellipses). The terrestrial velocities are estimated using the GEONET sites for the period from January 2008 to July 2009 (blue arrows). The black dotted lines indicate the boundaries of the block, though some boundaries are uncertain (e.g., the PHS-IM and the PHS-IA boundaries). The green regions (a) and (b) indicate the areas for the cross section shown in Fig. 5

System (GEONET) F3 solution from January 2008 to July 2009 (Nakagawa et al. 2009). The consistency of seafloor results with the regional velocity field of the GEONET in Fig. 4 supports for the validation of our seafloor results.

The reason why the confidence interval of the rate at SAGA is smaller than that at BOSS is due to not only the number of the observation epochs but also the oceanographic condition. The condition was usually better in the Sagami Bay than off the Boso Peninsula where the Kuroshio Current would affect the sound speed.

\section{Discussion}

First, we compared the result at BOSS before the Tohokuoki earthquake with the plate kinematics models. Because BOSS is located in the trench side of the volcanic front and away from block boundaries, slip deficits on the plate boundaries cause no significant deformation at BOSS except on the PAC-PHS boundary. In fact, a southward displacement of up to $0.1 \mathrm{~cm} /$ year is expected at BOSS from the slip deficit on the PHS-NA boundary faults listed in Nishimura (2011), whereas the PAC-PHS boundary has possibility to cause a westward displacement of approximately $1-2 \mathrm{~cm} /$ year. However, the geodetic observations

Table 3 Velocities with respect to the Eurasian plate with component variances and covariances

\begin{tabular}{|c|c|c|c|c|c|c|}
\hline \multirow[t]{2}{*}{ Site name } & \multirow[t]{2}{*}{ Epochs } & \multicolumn{2}{|c|}{ Velocity (cm/year) } & \multicolumn{3}{|c|}{ Variance and covariance $\left(\mathrm{cm}^{2} /\right.$ year $\left.{ }^{2}\right)$} \\
\hline & & E-ward & $\mathrm{N-ward}$ & $\overline{\operatorname{Var}(\mathrm{E})}$ & $\operatorname{Var}(\mathrm{N})$ & $\operatorname{Cov}(E, N)$ \\
\hline BOSS & Sep 2007-Nov 2010 & $-3.5 \pm 1.1$ & $1.8 \pm 1.1$ & 1.11 & 1.26 & 0.06 \\
\hline \multirow[t]{2}{*}{ SAGA } & Jan 2005-Mar 2011 & $-3.1 \pm 0.3$ & $2.4 \pm 0.3$ & 0.10 & 0.10 & 0.01 \\
\hline & Feb 2012-Apr 2015 & $-2.2 \pm 0.7$ & $1.7 \pm 0.9$ & 0.44 & 0.85 & 0.10 \\
\hline
\end{tabular}


on the islands have little resolution in the slip deficit on the PAC-PHS boundary. We therefore made the assumption that the deficit rate is zero tentatively.

The Euler vector of the rigid PHS had been evaluated in several models. Estimated values of velocity at BOSS are shown in Table 4. Seno et al. (1993) determined the velocities of the PHS using the earthquake slip vectors including northern boundaries of the PHS. It led to the NUVEL-1A model (DeMets et al. 1994), in which the PHS is expected to move at a rate of $0.7 \mathrm{~cm} /$ year westward and $0.7 \mathrm{~cm} /$ year northward relative to the ITRF at BOSS. On the contrary, the MORVEL model and the REVEL model were proposed from geodetic data by DeMets et al. (2010) and Sella et al. (2002), respectively. According to these models, BOSS moves relative to the ITRF at a rate of $2.4 \mathrm{~cm} /$ year westward and $1.3 \mathrm{~cm} /$ year northward and a rate of $2.2 \mathrm{~cm} /$ year westward and $1.3 \mathrm{~cm} /$ year northward, respectively. The residuals of the observed velocity to the models are statistically significant. The eastward component of the residuals is unaccountable even if the PAC-PHS interface is assumed to be locked. That is because the slip deficit on the PAC-PHS interface would cause the westward deformation at BOSS, as Sella et al. (2002) had already pointed out at the islands in the Izu-Bonin arc. They thus considered the residuals as non-rigid plate deformation such as spreading of the back-arc basin.

Whereas these models had estimated the motion of the PHS from geodetic data at only several sites far from its boundaries, Nishimura (2011) used additional sites near the boundaries to estimate rigid velocities and elastic deformation of the tectonic blocks simultaneously. In this block kinematics model, back-arc rift along the Izu-Bonin Trench was taken account as well. The fore-arc along the Izu-Bonin Trench is considered as a rigid block separated from the PHS, called Izu arc block (IA). At BOSS, the IA is calculated to move at a rate of $1.3 \mathrm{~cm} /$ year westward and $1.4 \mathrm{~cm} /$ year northward relative to the ITRF.

Although our result is quantitatively consistent with the velocities derived from both the NUVEL-1A and Nishimura's model, the difference between these models is emphasized in the easternmost part of the Nankai Trough. In this region, the strong coupling on the plate

Table 4 Comparison of observed velocities at BOSS with model velocities relative to the ITRF2005

\begin{tabular}{lll}
\hline Observation/model & \multicolumn{2}{l}{ Velocity at BOSS (cm/year) } \\
\cline { 2 - 3 } & E-ward & N-ward \\
\hline Observation (this study) & $-1.0 \pm 1.1$ & $0.5 \pm 1.1$ \\
PHS in NUVEL-1A & -0.7 & 0.7 \\
PHS in MORVEL & -2.4 & 1.3 \\
PHS in REVEL & -2.2 & 1.3 \\
IA in Nishimura (2011) & -1.3 & 1.4 \\
\hline
\end{tabular}

boundary was indicated by Yokota et al. (2015) from the observed displacement rates at the seafloor sites TOK1 and TOK2. According to them, the velocity obtained at TOK2 was significantly larger than the velocity of the PHS in the NUVEL-1A model. Thus, they pointed out that the motion of the IM should be considered. On the basis of Nishimura's model, the velocity at TOK2 is almost as large as that of both the PHS and the IM, despite the uncertainty about the location of the PHS-IM boundary. It supports the Nishimura's model, though more direct evidences by seafloor observation in the southwestern part of the IM are needed to clarify the tectonics of the subducting IM.

On the other hand, SAGA is located near two block boundaries. One is the Sagami Trough and the other divides the IM from the IA in the west side of the Sagami Bay. Figure 5 plots the cross section of the observed displacement rates relative to the EU. Along the Sagami Trough, the IA subducts northward (Fig. 5a), almost perpendicular to the trough (No et al. 2014). In the western boundary between the Sagami Bay (on the IA) and the Izu Peninsula (on the IM), the left lateral strike slip fault is indicated (Fig. 5b), as the 1980 Izu-Hanto-Toho-oki earthquake (M6.7) had occurred on a portion of the boundary (e.g., Takeo, 1988; Nishimura et al. 2007).

In order to estimate the slip deficit rate on the IM-IA boundary fault, we calculated the northward component of the surface deformation in an elastic half-space by the method of Okada (1992), applying back slip model (Savage, 1983). The geometry and location of the faults are the same as the IM-IA boundary faults indicated in Table 2 of Nishimura (2011), but depth is set to $0 \mathrm{~km}$. The four green lines in Fig. 5a indicate the result with the coupling rate of $0,50,80$, and $100 \%$. The results suggest that deformation with $50-80 \%$ coupling fits to the observed data, the same consequence as Nishimura's estimation. Therefore, the fault in the western side of the Sagami Bay is coupled with the deficit rate of a few centimeters per year, and thus, strain is accumulated.

After the Tohoku-oki earthquake, we performed four epochs of the observation at BOSS. The change of the displacement rates before and after the earthquake is not significant. Thus, we assumed that the postseismic deformation of the Tohoku-oki earthquake would cause no significant movement at BOSS. Then, comparing the average positions relative to the IA before and after the Tohoku-oki earthquake, we derived the eastward coseismic displacement of $3.9 \pm 2.0 \mathrm{~cm}$ at BOSS. We also detected the eastward coseismic displacement of about $10 \mathrm{~cm}$ at SAGA. According to the coseismic slip model estimated by Iinuma et al. (2012), coseismic displacements of $4.5 \mathrm{~cm}$ eastward and of $12 \mathrm{~cm}$ east-southeastward were estimated at BOSS and SAGA, respectively, which are both consistent with our results. 


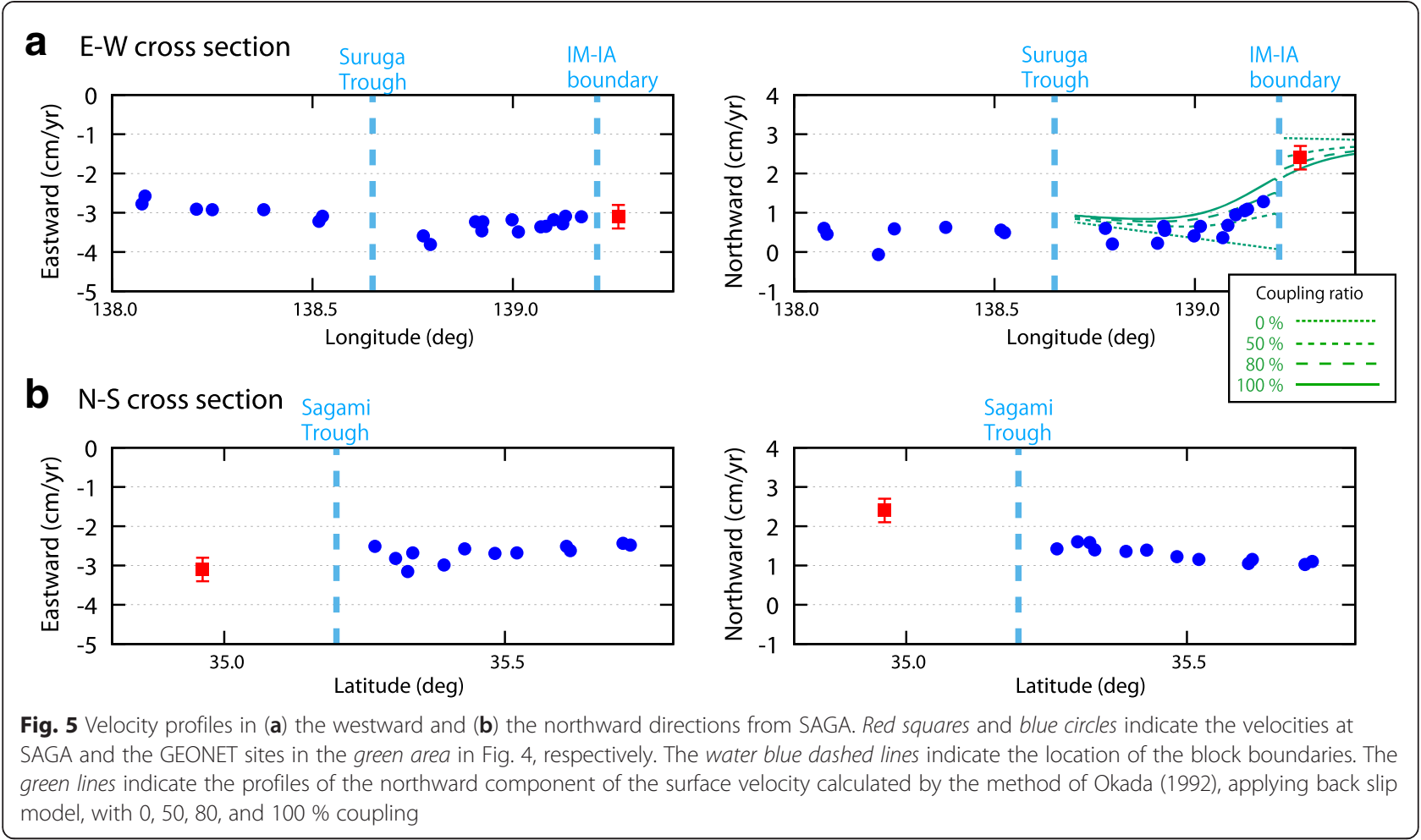

The displacement rate at SAGA after the earthquake (specifically 2012-2015) slightly changed from the rate before the earthquake, though the difference of $0.8 \pm 0.7 \mathrm{~cm} /$ year eastward and $0.7 \pm 0.9 \mathrm{~cm} /$ year southward is almost as small as the confidence level. The change is considered to be caused by the postseismic deformation of the event (e.g., Wang et al. 2012), like other geodetic sites in Japan (e.g., Ozawa et al. 2012; Watanabe et al. 2014). At the GEONET sites Niijima and Toshima on the islands in the IA, the difference between the displacement rates before (from January 2008 to July 2009) and after the Tohoku-oki earthquake (from January 2013 to January 2015) was approximately $0.9 \mathrm{~cm} /$ year eastward and $0.2-0.3 \mathrm{~cm} /$ year southward, which is consistent with SAGA.

\section{Conclusions}

We have performed the GPS-acoustic observations at BOSS and SAGA, and detected the movements before and after the Tohoku-oki earthquake. Because almost all part of the PHS is covered with ocean and many islands on this plate are volcanic, geodetic data at the non-volcanic seafloor sites provided an essential role to investigate the kinematics in the southern Kanto area. The result at BOSS before the Tohoku-oki earthquake suggested that the motion of the fore-arc of the PHS along the Izu-Bonin Trench is different from the rigid PHS, which is in good agreement with the model by Nishimura (2011). It thus contributed to clarify the velocity of the PHS (or the IA) subducting along the Sagami Trough in an oblique direction, which leads to more concrete understandings of the strain accumulation on the PHS-NA interface. Meanwhile, the result at SAGA before the earthquake provided the evidence of the slip deficit of a few centimeters per year on the IM-IA boundary fault from the oceanic plate.

From the observations after 2011, significant coseismic displacements associated with the Tohoku-oki earthquake were detected at both sites, whose values are consistent with the slip distribution model. Comparing the postseismic displacement rate after 2012 with that before the Tohoku-oki event, the significant postseismic movement toward the east was detected at SAGA.

While this paper determined the velocity of the PHS along the Sagami Trough, the subducting velocity along the Nankai Trough still has ambiguity. The ambiguity of the kinematics models will be reduced by further observations near the troughs, e.g., around the Zenisu Ridge, simultaneously determining the location of the IM-IA boundary.

\section{Abbreviations}

CL: confidence level; CTD: conductivity temperature depth profiler; EU: Eurasian plate; GEONET: GNSS Earth Observation Network System; GNSS: global navigation satellite system; GPS: global positioning system; IA: Izu arc block; IM: Izu microplate; ITRF: International Terrestrial Reference Frame; JCG: Japan Coast Guard; NA: North American plate; PAC: Pacific plate; PHS: Philippine Sea plate; XCTD: expendable conductivity temperature depth profiler; XBT: expendable bathythermograph.

\section{Competing interests}

The authors declare that they have no competing interests. 


\section{Authors' contributions}

SW, TI, and YY proposed the topic, carried out the observation, processed the data, and evaluated the accuracy of the results. SW interpreted the data and wrote the manuscript. All authors read and approved the final manuscript.

\section{Acknowledgements}

We thank the Geospatial Information Authority of Japan (GSI) for providing us with the GPS data as terrestrial reference sites for kinematic GPS analysis and releasing daily coordinates of the sites on GSI's website. We also thank Dr. Oscar L. Colombo of the NASA Goddard Space Flight Center for providing us with the kinematic GPS software IT (Interferometric Translocation) (Colombo, 1998). We wish to express gratitude to Professor Akira Asada of Institute of Industrial Science, University of Tokyo, and Dr. Masashi Mochizuki of National Research Institute for Earth Science and Disaster Prevention for the continuous collaboration to develop the GPS-A technique; Dr. Takeshi linuma of the Japan Agency for Marine-Earth Science and Technology for calculating the coseismic displacements at our sites; and Dr. Azusa Nishizawa of Japan Coast Guard for the valuable comments. A lot of staff members of the Hydrographic and Oceanographic Department of Japan Coast Guard, including the crew of S/Ns Shoyo, Takuyo, Meiyo, and Kaiyo, have been supporting us in observations and data analyses. Comments from Professor Jack Loveless of the Smith College and an anonymous reviewe have improved the paper substantially. Some figures were produced with the GMT software (Wessel and Smith, 1991).

\section{Received: 20 August 2015 Accepted: 29 October 2015}

\section{Published online: 11 November 2015}

\section{References}

Altamimi Z, Collilieux X, Legrand J, Garayt B, Boucher C (2007) ITRF2005: a new release of the international terrestrial reference frame based on time series of station positions and earth orientation parameters. J Geophys Res 112 , B09401. doi:10.1029/2007JB004949

Ando M (1975) Source mechanism and tectonic significance of historical earthquakes along the Nankai Trough, Japan. Tectonophysics 27:119-140. doi:10.1016/0040-1951(75)90102-X

Asada A, Yabuki T (2001) Centimeter-level positioning on the seafloor. Proc Jpn Acad Ser B 77:7-12

Colombo OL (1998), Long-distance kinematic GPS. In: Teunissen PJG, Kleusberg A (ed) GPS for Geodesy, 2nd Edition. Springer-Verlag Berlin Heidelberg New York, pp 537-567

DeMets C, Gordon RG, Argus DF, Stein S (1994) Effect of recent revisions to the geomagnetic reversal time scale on estimates of current plate motions. Geophys Res Lett 21:2191-2194

DeMets C, Gordon RG, Argus DF (2010) Geologically current plate motions. Geophys J Int 181:1-80. doi:10.1111/j.1365-246X.2009.04491.x

Fujita M, Ishikawa T, Mochizuki M, Sato M, Toyama S, Katayama M, Matsumoto Y, Yabuki T, Asada A, Colombo OL (2006) GPS/Acoustic seafloor geodetic observation: method of data analysis and its application. Earth Planets Space 58:265-275. doi:10.1186/BF03351923

linuma T, Hino R, Kido M, Inazu D, Osada Y, Ito Y, Ohzono M, Tsushima H, Suzuki S, Fujimoto H, Miura S (2012) Coseismic slip distribution of the 2011 off the Pacific Coast of Tohoku Earthquake (M9.0) refined by means of seafloor geodetic data. J Geophys Res 117:B07409. doi:10.1029/2012JB009186

Izumi N, Nishizawa A, Horiuchi D, Kido Y, Nakata T, Goto H, Watanabe M, Suzuki Y (2013) 3D bathymetric image along the Sagami Trough and the Boso Triple Junction area deduced from 150 meter grid DEM (in Japanese). Rep Hydrogr Oceanogr Res 50:126-139

Kido M, Fujimoto H, Miura S, Osada Y, Tsuka K, Tabei T (2006) Seafloor displacement at Kumano-nada caused by the 2004 off Kii Peninsula earthquakes, detected through repeated GPS/acoustic surveys. Earth Planets Space 58:911-915

Kido M, Osada Y, Fujimoto H, Hino R, Ito Y (2011) Trench-normal variation in observed seafloor displacements associated with the 2011 Tohoku-Oki earthquake. Geophys Res Lett 38, L24303. doi:10.1029/2011GL050057

Matsumoto Y, Fujita M, Ishikawa T, Mochizuki M, Yabuki T, Asada A (2006) Undersea co-seismic crustal movements associated with the 2005 Off Miyagi Prefecture Earthquake detected by GPS/Acoustic seafloor geodetic observation. Earth Planets Space 58:1573-1576. doi:10.1186/BF03352663
Matsumoto Y, Fujita M, Ishikawa T (2008) Development of multi-epoch method for determining seafloor station position (in Japanese). Rep Hydrogr Oceanogr Res 26:16-22

Nakagawa H, Toyofuku T, Kotani K, Miyahara B, Iwashita C, Kawamoto S, Hatanaka Y, Munekane H, Ishimoto M, Yutsudo T, Ishikura N, Sugawara Y (2009) Development and validation of GEONET new analysis strategy (Version 4) (in Japanese). J Geographical Survey Inst 118:1-8, http://www.gsi.go.jp/REPORT/ JHO/vol118-main.html

Nishimura T (2011) Back-arc spreading of the northern Izu-Ogasawara (Bonin) Islands arc clarified by GPS data. Tectonophysics 512:60-67. doi:10.1016/j.tecto.2011.09.022

Nishimura T, Sagiya T, Stein RS (2007) Crustal block kinematics and seismic potential of the northernmost Philippine Sea plate and Izu microplate, central Japan, inferred from GPS and leveling data. J Geophys Res 112, B05414. doi:10.1029/2005JB004102

No T, Takahashi N, Miura S, Yamashita M, Kido Y, Kodaira S (2014) Deformation of the Manazuru Knoll in Sagami Bay, central Japan, associated with subduction of the Philippine Sea plate. Earth Planets Space 66:109. doi:10.1186/1880-5981-66-109

Okada Y (1992) Internal deformation due to shear and tensile faults in a half-space. Bull Seism Soc Am 75:1135-1154

Ozawa S (2014) Shortening of recurrence interval of Boso slow slip events in Japan. Geophys Res Lett 41:2762-2768. doi:10.1002/2014GL060072

Ozawa S, Nishimura T, Munekane H, Suito H, Kobayashi T, Tobita M, Imakiire T (2012) Preceding, coseismic, and postseismic slips of the 2011 Tohoku earthquake, Japan. J Geophys Res 117, B07404. doi:10.1029/2011JB009120

Sagiya T (1999) Interplate coupling in the Tokai District, Central Japan, deduced from continuous GPS data. Geophys Res Lett 26:2315-2318

Sato M, Ishikawa T, Ujihara N, Yoshida S, Fujita M, Mochizuki M, Asada A (2011a) Displacement above the hypocenter of the 2011 Tohoku-oki earthquake. Science 332:1395. doi:10.1126/science.1207401

Sato M, Saito H, Ishikawa T, Matsumoto Y, Fujita M, Mochizuki M, Asada A (2011b) Restoration of interplate locking after the 2005 Off-Miyagi prefecture earthquake, detected by GPS/acoustic seafloor geodetic observation. Geophys Res Lett 38, L01312. doi:10.1029/2010GL045689

Sato M, Fujita M, Matsumoto Y, Saito H, Ishikawa T, Asakura T (2013a) Improvement of GPS/acoustic seafloor positioning precision through controlling the ship's track line. J Geod 87:825-842. doi:10.1007/s00190-013-0649-9

Sato M, Fujita M, Matsumoto Y, Ishikawa T, Saito H, Mochizuki M, Asada A (2013b) Interplate coupling off northeastern Japan before the 2011 Tohoku-oki earthquake, inferred from seafloor geodetic data. J Geophys Res 118:1-10. doi:10.1002/jgrb.50275

Savage JC (1983) A dislocation model of strain accumulation and release at a subduction zone. J Geophys Res 88:4984-4996. doi:10.1029/JB088iB06p04984

Sella GF, Dixon TH, Mao A (2002) REVEL: a model for recent plate velocities from space geodesy. J Geophys Res 107(B4):2081. doi:10.1029/2000JB000033

Seno T, Stein S, Gripp AE (1993) A model for the motion of the Philippine Sea plate consistent with NUVEL-1A and geological data. J Geophys Res 98:17941-17948

Spiess FN, Chadwell CD, Hildebrand JA, Young LE, Purcell GH Jr, Dragert H (1998) Precise GPS/Acoustic positioning of seafloor reference points for tectonic studies. Phys Earth and Planet Inter 108:101-112. doi:10.1016/S00319201(98)00089-2

Tadokoro K, Ikuta R, Watanabe T, Ando M, Okuda T, Nagai S, Yasuda K, Sakata $T$ (2012) Interseismic seafloor crustal deformation immediately above the source region of anticipated megathrust earthquake along the Nankai Trough, Japan. Geophys Res Lett 39, L10306. doi:10.1029/ 2012GL051696

Takeo M (1988) Rupture process of the 1980 Izu-Hanto-Toho-Oki earthquake deduced from strong motion seismograms. Bull Seism Soc Am 78(3):1074-1091

Taylor B, Klaus A, Moore GF, Murakami F, Okamura Y (1991) Structural development of the Sumisu Rift, Izu-Bonin Arc. J Geophys Res 96(B10):16113-16129

Wang K, Hu Y, He J (2012) Deformation cycles of subduction earthquake in a viscoelastic Earth. Nature 484:327-332. doi:10.1038/nature11032

Watanabe S, Sato M, Fujita M, Ishikawa T, Yokota Y, Ujihara N, Asada A (2014) Evidence of viscoelastic deformation following the 2011 Tohoku-oki earthquake revealed from seafloor geodetic observation. Geophys Res Lett 41:5789-5796. doi:10.1002/2014GL061134

Wessel P, Smith WHF (1991) Free software helps map and display data. Eos Trans AGU 72:441. doi:10.1029/90EO00319

Yasuda K, Tadokoro K, Ikuta R, Watanabe T, Nagai S, Okuda T, Fujii C, Sayanagi K (2014) Interplate locking condition derived from seafloor geodetic data at 
the northernmost part of the Suruga Trough, Japan. Geophys Res Lett 41:5806-5812. doi:10.1002/2014GL060945

Yokota Y, Ishikawa T, Sato M, Watanabe S, Saito H, Ujihara N, Matsumoto Y, Toyama S, Fujita M, Yabuki T, Mochizuki M, Asada A (2015) Heterogeneous interplate coupling along the Nankai Trough, Japan, detected by GPSacoustic seafloor geodetic observation. Prog Earth Planet Sci 2:10. doi:10.1186/s40645-015-0040-y

Submit your manuscript to a SpringerOpen ${ }^{\odot}$ journal and benefit from:

- Convenient online submission

- Rigorous peer review

- Immediate publication on acceptance

- Open access: articles freely available online

- High visibility within the field

- Retaining the copyright to your article

Submit your next manuscript at $\gg$ springeropen.com 